The light level the authors used was 20 times lower than that produced by a streetlight, showing that even small changes can have an impact on animal development.

Proc. R. Soc. B 280, 20123017 (2013)

\section{NEUROSCIENCE}

\section{Protein makes she sound like he}

Levels of a brain protein could help to explain sex differences in some animal vocalizations, including in human language.

In a study of newborn rats, Michael Bowers at the University of Maryland School of Medicine in Baltimore and his colleagues identified a relationship between differences in the level of protein Foxp2 in the male and female brain to the ultrasonic distress calls that pups make when they are separated from their mothers. Male pups - which have higher Foxp2 levels in multiple brain regions - call more frequently and at lower pitches than their female siblings. When Foxp2 levels were reduced in males and increased in females, these differences were reversed. The authors also found sex differences in the protein in human brain samples that correlates with earlier language acquisition by girls. J. Neurosci. 33, 3276-3283 (2013)

\section{MOLECULAR BIOLOGY}

\section{Dance of DNA- binding proteins}

Contortions of a DNA strand caused by the binding of a protein affect how a second protein binds - a phenomenon that may regulate gene expression.

Sunney Xie at Harvard University in Cambridge, Massachusetts, and his group used fluorescence microscopy to observe interactions between proteins and DNA at the singlemolecule level. The authors showed that one protein could stabilize or destabilize a second protein's attachment to DNA. The proteins do not interact directly. Rather, one widens or narrows grooves along the DNA helix, affecting the binding of another protein as far away as 30 base pairs. Such allosteric interactions also occurred in live bacterial cells.

Proteins that bind

DNA are often involved

in gene regulation, and these interactions may be a mechanism in its fine-tuning. Science 339, 816-819 (2013)

\section{MEDICINE}

\section{Microbes make melamine toxic}

Melamine, the chemical that achieved infamy in 2008 for the poisoning of children's milk in China, owes its toxicity in part to gut bacteria.

Wei Jia and Aihua Zhao of Shanghai Jiao Tong University in China and their group show that the toxicity of melamine in rats is reduced and its excretion increased if gut microbes are suppressed with antibiotics. They also show that the bacterium Klebsiella terrigena, which the authors had cultured from rat faeces, converts melamine to cyanuric acid in vitro. This acid - which forms crystals with melamine - is a key component of the kidney stones linked to both melamine-related kidney failure and death.

The authors suggest that melamine toxicity may depend on the composition of an organism's gut microbes. Sci. Transl. Med. 5, 172ra22 (2013)

\section{EVOLUTION \\ Predictable bacterial diversity}

Similar, and even identical, mutations underlie the metabolic diversification of independently evolving populations of the bacterium Escherichia coli.

Matthew Herron and Michael Doebeli at the

COMMUNITY CHOICE

The most viewed papers in science

\title{
Hydrogen on demand
}

\section{HIGHLY READ \\ on pubs.acs.org in January}

Silicon reacts extremely slowly with water to produce hydrogen gas, but 10-nanometrewide silicon particles react 1,000 times faster.

Mark Swihart, Paras Prasad and their colleagues at the State University of New York at Buffalo report that 1 gram of powdered silicon can generate about 2 litres of hydrogen in about 45 seconds - a rate that is sufficient for systems to produce hydrogen fuel on demand from water.

The authors say that the process they used to generate the silicon powders - breaking up silane gas with lasers - can produce kilograms of powder in an hour, which may mean that the process has the potential to move beyond niche applications.

Nano Lett. 13, 451-456 (2013)

University of British Columbia in Vancouver, Canada, exposed E. coli to a mixture of glucose and acetate and found that competition for the carbon sources caused the bacteria, over about 1,200 generations, to evolve into two ecologically and metabolically different strains. This occurred in three independent evolution experiments. The authors sequenced the genomes of the three bacterial populations at 16 points during their evolution. They found many similar and a few identical mutations that underlay the evolution of diversity in the three experiments.

The findings suggest that this evolution is a predictable process that is driven by natural selection.

PLoS Biol. 11, e1001490 (2013)

Tough life in
the tropics

The tropics host a much smaller number of invasive species than temperate regions, possibly because predation in the tropics is more intense.

Amy Freestone of Temple University in Philadelphia, Pennsylvania, and her colleagues conducted field

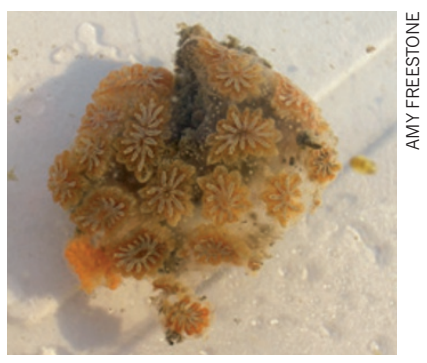

experiments off the coast of Connecticut and Panama. They allowed populations of nonnative tunicates (pictured) - sessile marine creatures also known as sea squirts - to grow on plastic plates, blocked predators such as crabs and fish from reaching some of the plates, and looked at the effects of predation on species richness. Predated plates in the tropics had fewer non-native tunicate species than those in temperate areas.

The results generally support the idea that food webs in the tropics are more diverse and interconnected than those in temperate latitudes, making it harder for non-native species to establish themselves.

Ecology http://dx.doi. org/10.1890/12-1382.1 (2013)

\section{$\rightarrow$ NATURE.COM}

For the latest research published by Naturevisit:

www.nature.com/latestresearch 